\title{
An Empirical Study of the Impacts of Geographic and Cultural Distance on Chinese ODI
}

\author{
J.H. Qi ${ }^{\text {a }}$ Y. Zhao ${ }^{\mathrm{b}}$ and $\underline{\text { Z.Y. Zhang }}$ \\ ${ }^{a}$ School of Economics, Shandong University, China \\ ${ }^{b}$ School of Economics, Renmin University of China, and \\ ${ }^{c}$ School of Business, Edith Cowan University, Australia \\ Email: qijianhong@sdu.edu.cn (Qi),joyong@ruc.edu.cn (Zhao), and \\ zhaoyong.zhang@ecu.edu.au (Zhang)
}

\begin{abstract}
Since the reform and opening-up started in the end of the 1970s, especially after Deng's southern tour in the early 1990s, China has achieved remarkable success in attracting foreign direct investment (FDI), and become one of the top destinations in the world for FDI since 2003. By 2013, the utilized FDI in China has reached USD118.7 billion from nearly null level. The recent UNCTAD report shows that China became the top destination for inward FDI again in 2014, with an estimated amount of over US\$128 billion of FDI received, despite concerns of China's economic slowdown. With China's rapidly integrating with the global economy, its outward FDI has also picked up rapidly in recent decades, especially since China's WTO entry in 2001, to make overseas acquisitions to gain technology and market access and international experience. Over the past few decades China has transformed into a major source country of FDI in the world, and become the third largest source of foreign direct investment after the United States and Japan since 2012.

In this study we attempt to investigate empirically the impacts of geographic and cultural distance on Chinese outward direct investment (ODI). It is found that Chinese ODI is negatively correlated with both geographic and cultural distance based on the tests using the full sample of all the recipient countries. Furthermore, we investigate the mechanisms through which the impact of cultural and geographic distance is exerted. The results indicate that geographic distance bears significantly negative impacts on ODI in the countries of low geographic distance, while it encourages OFDI into countries with high geographic distance. In addition, cultural distance is found to discourage OFDI through its impact on bilateral trade.
\end{abstract}

Keywords: $\quad$ Outward foreign direct investment, Chinese economy, geographic and cultural distance 


\section{INTRODUCTION}

Since the reform and opening-up started in the end of the 1970s, especially after Deng Xiaoping's southern tour in the early 1990s, China has achieved remarkable success in attracting foreign direct investment (FDI), and become one of the top destinations in the world for FDI since 2003. By 2013, the utilized FDI in China has reached USD118.7 billion from nearly null level. The recent UNCTAD report shows that China became the top destination for inward FDI again in 2014, with an estimated amount of over US\$128 billion of FDI received, despite concerns of China's economic slowdown. With China's rapidly integrating with the global economy, its outward FDI has also picked up rapidly in recent decades, especially since China's WTO entry in 2001, to make overseas acquisitions to gain technology and market access and international experience. As presented in Figure 1, over the past few decades China has transformed into a major source country of FDI in the world, and become the third largest source of foreign direct investment after the United States and Japan since 2012. In 2014 China's outward direct investment was about to catch up with its inward FDI for the first time, thanks to the accelerated economic transformation and it sustained rapid economic expansion. However, it is noted that the Chinese ODI is widely distributed but imbalanced geographically. Figure 2 presents the geographical distribution of the Chinese ODI in 2003-2012. In absolute terms, the bulk of investment has gone to Asia, especially to Hong Kong. As it can be seen in Figure 2 that Asia accounts for over 60 per cent of China's total ODI during this period, with Hong Kong alone accounting for over 50 per cent, followed by Europe, Latin America and the Caribbean. The proportion that Africa took is unstable during the period, ranging from 2.4 percent in 2009 the lowest to as high as about 10 percent in 2008. In terms of growth rate, investment in Europe and American countries has grown at an accelerating rate in the wake of the current financial crisis, far outpacing the growth of OFDI in Asia.

The locational determinants of OFDI have been traditionally attributed to economic (Goldberg and Kolstad, 1995; Zhang and Daly, 2011), geographic (Mucchielli and Pei, 2011), cultural (Hofstede, 1980; Schwartz, 1994), and political factors (Mucchielli and Pei, 2011). In terms of determinants of Chinese ODI, studies have revealed inconclusive or even conflicting results. For instance, Chinese ODI is found to be negatively correlated to the market size of its developing host countries, yet its correlation with the wage rates in the host countries is found to be indeterminate (Cheung and Qian, 2009). One may argue that the host country's market size (proxied by GDP, population size), and the competitive wage level attract Chinese OFDI. However, this argument is not convincing, given the fact that China now has the world's largest population and second largest

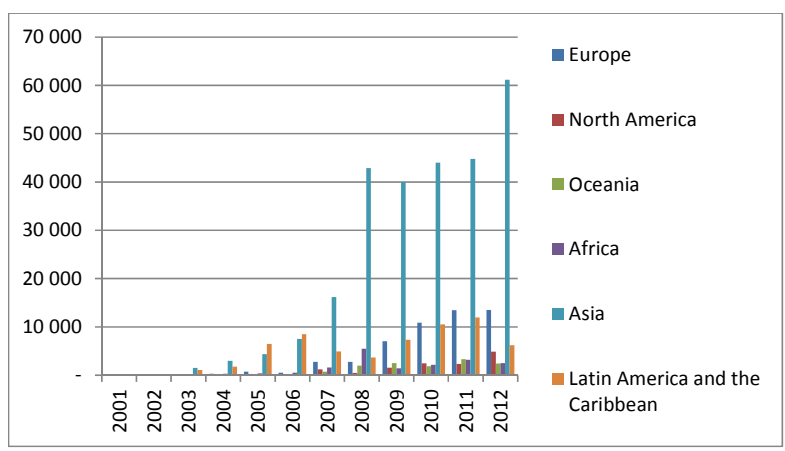

Figure 1. China's inward and outward FDI, 19902014 (in US\$ Million). Source: UNCTAD GDP, and that the wage rate in China is relatively

low when compared with many recipient countries. From a political point of view, some studies argue that state-owned enterprises (SOEs) play a predominant role in Chinese OFDI, with the strategic intent to explore natural resources which are considered essential to national economic development such as minerals and petroleum and to acquire technology and managerial skills. Consequently, these studies conclude that such motivations of OFDI and the corresponding government policies overshadow the economic, geographic and cultural factors (Mucchielli and Pei, 2011). However, the predominance of SOEs has been declining, which is evidenced by the share of Chinese OFDI stock dropping from more than $90 \%$ in 2003 to $66.2 \%$ in 2010 . 1The role of political factors will be expected to continue to weaken with further reduction in administrative obstacles (Davies, 2010). As far as geographic factors are concerned, many researchers have concluded that geographic distance discourages Chinese ODI because of transportation costs (Mucchielli and Pei, 2011). With respect to culture, conclusions and explanations again differ widely among researchers. On one hand, Zaheer (1995) suggests that cultural distance may result in a liability of foreignness for a multi-national enterprise (MNE) which is foreign to local culture. Hence, a negative relationship between cultural distance and ODI is expected. On the other hand, other researchers (Evans and Mavondo, 2002) find a positive relationship between cultural distance and ODI, as cultural distance may bring the benefit of foreignness to an MNE (Evans and Mavondo, 2002), deriving from the asset exploitation and asset exploration. The interaction of the two effects might well mean a non-linear relationship between cultural distance and ODI. 
Existing studies have provided us with a solid basis, yet also left much room for further research. First, the latest development of Chinese ODI suggests that research interest should shift somewhat from economic and political factors to geographic and cultural factors as the latter are likely to play an increasing role in determining Chinese ODI location choice in the future. Second, existing studies on the impact of geographic and cultural distance on ODI focus mainly on developed countries' experiences. Few studies in this area involve Chinese ODI. Third, existing literature seldom studies the mechanisms through which geographic and cultural distance impacts ODI. For instance, does geographic

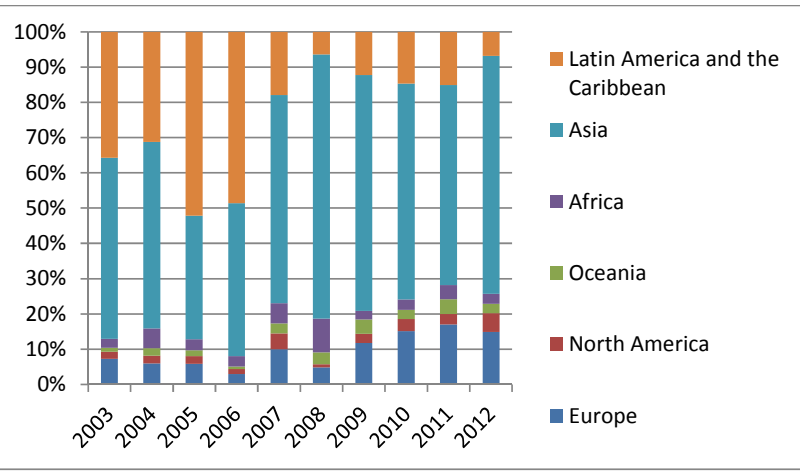

Figure 2. Geographical distribution of China's ODI 2003-2012. Source: UNCTAD distance affect ODI indirectly through its direct impact on culture and trade? Or does cultural distance affect trade, which in turn impacts OFDI? Fourth, in empirical implementation, most researchers tend to consider recipient countries indiscriminately in exploring the effect of both geographic and cultural distance on ODI. In the context of China, we argue that the impact of geographic and cultural distance on ODI can't be generalized. As mentioned above, most Chinese OFDI has gone to Asian countries with lower geographic and cultural distance from China, but Chinese OFDI has grown most rapidly in Europe and North American countries which are further away.

This paper contributes to existing literature in several aspects. First, the overall effect of geographic and cultural distance on Chinese OFDI is examined by studying the whole sample of recipient countries. Second, sample countries are divided into subsamples by geographic and cultural distance and are studied separately to investigate their respective impact. Third, efforts are made to explore the mechanisms through which geographic and cultural distance impact Chinese OFDI's location choice.

This paper is organized as follows. Section 2 proposes four hypotheses of the locational choice of OFDI. Section 3 describes the methodology and data. Section 4 reports the empirical results. The final section concludes the research and offers policy implications.

\section{THEORY AND HYPOTHESES}

This study focuses on the impact of geographic and cultural distance on Chinese OFDI. Based on the existing literature, we propose the following four hypotheses.

\section{(1) Geographic distance influences Chinese OFDI}

According to the classic gravity model, bilateral trade and investment flows are positively related to the size of the two economies under study, but are negatively related to their geographic distance (Tinbergen, 1962). The greater the geographic distance is, the less cultural similarity and likelihood of convergence there is. Likewise, the less the geographic distance is, the greater information asymmetry, management uncertainty and risk management cost are. Hence, OFDI is less willing to enter a market which is geographically remote from its home country. These general rules are expected to hold for Chinese OFDI. It follows that geographic distance could impede Chinese OFDI through cultural difference. At the same time, as a cost to trade, geographic distance discourages trade and thereby drives Chinese MNEs to tap the target markets via OFDI (Kolstad and Wiig, 2010). In summary, we propose the following hypotheses:

H1a: Chinese OFDI tends to favor countries with lower geographic distance;

H1b: Geographic distance indirectly reduces OFDI through cultural distance;

H1c: Geographic distance indirectly motivates FDI by discouraging trade.

(2) Cultural distance impacts Chinese OFDI

Cultural distance could result in an "outsider disadvantage", due to the difficulties in perceiving and interpreting cultural and environmental barriers and replicating tacit knowledge in the host country, as well as the obstacles in corporate coordination and governance. With high cultural distance, it is difficult for managers of multinationals to be knowledgeable of the host country's cultural environment, leading to misunderstandings of cultural information and raising information interpretation cost (Dow and Karunaratna, 2006). To compete in the world market, multinationals need to replicate some tacit knowledge in the host country. Cultural similarity is essential for such replication, without which the host country culture will turn 
into a noise disturbance (Schneider, 1989). Meanwhile, increasing cultural distance could bring about inconsistency or even conflict between the parent company and subsidiaries in market reaction, control systems, human capital policies and also highlights the problems of information asymmetry, incentive incompatibility, and agency by agreement (Lu and Beamish, 2004). Therefore, most scholars come to the conclusion that OFDI location choice is negatively related to cultural distance (Flores and Aguilera, 2007). However, cultural distance could hinder trade, and consequently impact OFDI indirectly (Korneliussena and Blasiusb, 2008). With Chinese OFDI, countries and regions of low cultural distance such as Hong Kong and Singapore have always ranked among the top 10 host countries. Therefore, we have the following two hypotheses:

$\mathrm{H} 2 \mathrm{a}$ : Chinese OFDI tends to favor countries with lower cultural distance;

$\mathrm{H} 2 \mathrm{~b}$ : Interaction of cultural distance and trade could hinder Chinese OFDI.

\section{(3) Economic factors influence Chinese OFDI}

According to Scaperlanda and Balougn (1983), the market size of the host country above a certain level would reward the economy of scale of the multinationals and attract OFDI inflow. However, it should be noted that this theory assumes that the capital of OFDI and the host country are homogeneous and dismisses considerations of difficulties due to cultural, linguistic, political and religious differences. Dunning (1996) shows that the absolute level of GDP is insignificant but GDP growth rate is statistically significant for OFDI from developing countries. Edward (2003) finds that Chinese OFDI favors countries featuring a smaller GDP per capita gap than China. According to the partial equilibrium analysis in international economics, it is widely acknowledged that OFDI could substitute for exports (Buckley and Casson, 1981). However, this may not be the case for China. Many studies have confirmed that China's exports and bilateral trade are both positively associated with its OFDI (Mucchielli and Pei, 2011) to the host country. Moreover, the top 20 recipient countries of Chinese OFDI in 2010 include different categories, including fast growing economies such as Russia, Brazil, South Africa, Iran and other "Next Eleven" countries, which are featuring close trade and economic relations with China such as the United States, Canada and other developed countries, as well as countries of similar economic development to China such as Myanmar, Thailand and Cambodia. In light of such diversity, we propose the following hypotheses regarding economic factors of Chinese OFDI:

H3a: Chinese OFDI is positively related to GDP growth in host countries;

H3b: Chinese OFDI is positively related to bilateral trade;

H3c: Chinese OFDI is negatively related to GDP per capita differential between China and the host country.

(4) Political factors influence Chinese OFDI

Political concerns are generally considered to be an important determinant of the location choice of OFDI because foreign investors, if unable to adapt their business strategies to host country's institutions, would not be able to operate smoothly to achieve profit maximization (Benvan et al., 2004). In addition, the economic organization the host country belongs to, the bilateral investment protection agreements (BIT) the host country has signed, the avoidance of double taxation agreement (ADT), trade barriers and FDI policies are the international economic institutional factors affecting OFDI location choice. Although some may argue that SOEs focus only on the exploration of natural resources and ignore other factors in undertaking OFDI to secure the long-run stable supply of resources (Mucchielli and Pei, 2011), it should be noted that the share of Chinese OFDI in the mining industry fell from $40.4 \%$ in 2006 to $8.3 \%$ in 2010 while the portion of SOEs of Chinese OFDI stock dropped from $81 \%$ to $66.2 \%$ during the same period. As a result, the role of SOEs in encouraging OFDI is becoming unimportant. Thus, we put forward the two hypotheses as follows.

H4a : The numbers of BITs and ADTs the host country has signed attract Chinese OFDI; $\mathrm{H} 4 \mathrm{~b}$ : The control of the Chinese government over OFDI is declining.

\section{METHODOLOGY AND THE MODEL}

The dependent variable of the model is annual Chinese OFDI inflows into the host countries. In line with the discussions and hypotheses in the preceding sections, the explanatory variables include geographic distance, cultural distance, time trend, the selected control variables, the interaction term of geographic distance and cultural distance, the interaction term of geographic distance and trade, the interaction term of cultural distance and trade. Specifically, they are:

Geographic distance (DIST) - Geographic distance in this study is defined as the straight-line distance between Beijing and the capital city of a host country, calculated with a "distance calculator", using the respective latitude and longitude of the two cities. ${ }^{2}$ We are interested in whether geographic distance 
encourages or discourages Chinese OFDI and to what extent. Cultural distance (CULT) -This paper follows Hofstede's (1980) ${ }^{3}$ conceptualization of cultural distance and Kogut and Singh's (1988) cultural distance index in measuring cultural distance. It is calculated with the following equation and Hofsted's dimensions of cultural distance.

$$
C D_{j}=\sum_{i=1}^{4}\left[\left(I_{i j}-I_{i C H}\right)^{2} / V_{i}\right] / 4
$$

where $C D_{j}$ is the cultural distance between the host country $j$ and China, $I_{i j}$ is country $j$ 's score on the $i$ th cultural dimension, $I_{i C H}$ is the score of the China on this dimension, and $V_{i}$ is the variance of the score of the dimension.

Incorporating both the crosssectional and time dimensions, panel data analysis could address the problem of omitted variable(s) and estimate time-invariant unobserved individual differences. Given the potential problems of heteroscedasticity associated with panel data, we perform the Wald test for heteroscedasticity, and the results are listed in Table 1 . Besides, the Hausman test suggests that the fixed effects model is the preferred model for our data in this study. Considering the fact that geographic and cultural distances are time invariant, especially over the short term, we employ the least square dummy variable model (LSDV) in our study wherein the

\begin{tabular}{|c|c|c|c|}
\hline Variables & LSDV1 & LSDV2 & LSDV3 \\
\hline LNDIST & $\begin{array}{c}-1.06^{* * *} \\
(-3.34)\end{array}$ & & $\begin{array}{c}-1.13 * * * \\
(-3.06)\end{array}$ \\
\hline CULT & & $\begin{array}{l}-1.16^{*} \\
(-1.81)\end{array}$ & $\begin{array}{c}-2.55^{* *} \\
(-2.10)\end{array}$ \\
\hline LNDIST*CULT & $\begin{array}{c}-0.06 \\
(-1.57)\end{array}$ & $\begin{array}{c}0.02 \\
(0.20)\end{array}$ & $\begin{array}{c}0.40 \\
(1.54)\end{array}$ \\
\hline LNDIST*LNTRADE & $\begin{array}{c}0.22 * * * \\
(2.70)\end{array}$ & & $\begin{array}{c}0.02 \\
(0.18)\end{array}$ \\
\hline CULT*LNTRADE & & $\begin{array}{c}0.21 * * * \\
(2.97)\end{array}$ & $\begin{array}{c}0.20 * * \\
(2.41)\end{array}$ \\
\hline LNTRADE & $\begin{array}{c}-0.26 \\
(-0.72)\end{array}$ & $\begin{array}{c}0.46 * * * \\
(3.05)\end{array}$ & $\begin{array}{c}0.30 \\
(0.62)\end{array}$ \\
\hline LNGDPD & $\begin{array}{l}-0.11 \\
(-0.75)\end{array}$ & $\begin{array}{c}-0.08 \\
(-0.50)\end{array}$ & $\begin{array}{c}-0.10 \\
(-0.64)\end{array}$ \\
\hline GDPG & $\begin{array}{l}-0.05 \\
(-1.19)\end{array}$ & $\begin{array}{c}-0.01 \\
(-0.35)\end{array}$ & $\begin{array}{l}-0.04 \\
(-1.02)\end{array}$ \\
\hline BIT & $\begin{array}{c}-0.34 \\
(-0.89)\end{array}$ & $\begin{array}{c}0.41 \\
(1.12)\end{array}$ & $\begin{array}{c}-0.02 \\
(-0.06)\end{array}$ \\
\hline ADT & $\begin{array}{c}-1.79 * * * \\
(-4.44)\end{array}$ & $\begin{array}{c}-1.48 * * * \\
(-3.68)\end{array}$ & $\begin{array}{c}-1.34 * * * \\
(-3.00)\end{array}$ \\
\hline SOE & $\begin{array}{c}-0.06 \\
(-0.02)\end{array}$ & $\begin{array}{c}1.45 \\
(0.45)\end{array}$ & $\begin{array}{c}0.36 \\
(0.11)\end{array}$ \\
\hline YEAR & $\begin{array}{c}0.47 * * \\
(2.58)\end{array}$ & $\begin{array}{c}0.53 * * * \\
(2.89)\end{array}$ & $\begin{array}{c}0.48 * * * \\
(2.65)\end{array}$ \\
\hline CONSTANT & $\begin{array}{c}-936.06 * * \\
(-2.54)\end{array}$ & $\begin{array}{c}-1064.06 * * * \\
(-2.87)\end{array}$ & $\begin{array}{c}-960.88 * * * \\
(-2.61)\end{array}$ \\
\hline Hausman test & 0.028 & 0.013 & 0.011 \\
\hline F-statistic & 23.30 & 22.77 & 20.22 \\
\hline R-squared & 0.44 & 0.43 & 0.45 \\
\hline Heteroscedasticity test & 0.000 & 0.000 & 0.000 \\
\hline Observations & 320 & 320 & 320 \\
\hline
\end{tabular}
time effect is accounted for by including a time trend. Hence, we have in the model "two-way fixed effects". In addition, given possible multicollinearity between geographic distance and culture distance, the two variables first enter the regression separately (LSDV 1 and LSDV 2) and then jointly (LSDV 3). Finally, to address the potential endogeneity problem of the trade variable, the one period lagged value of trade is applied in the model. The model is thus specified as:

$$
\begin{aligned}
& \operatorname{LNOFDI}_{i, j, t}=\beta_{0}+\beta_{1} \mathrm{LNDIST}_{i, j}+\beta_{2} C U L T_{i, j}+\beta_{3} \mathrm{LNDIST}_{i, j} * \mathrm{CULT}_{i, j} \\
& +\beta_{4} \mathrm{LNDIST}_{i, j} * \mathrm{LNTRADE}_{i, j, t-1}+\beta_{5} C U L T_{i, j} * \mathrm{LNTRADE}_{i, j, t-1}+\beta_{6} L N T R A D E_{i, j, t-1} \\
& +\beta_{7} \mathrm{LNGDPD}_{i, j, t-1}+\beta_{8} \operatorname{GDPG}_{i, t-1}+\beta_{9} \mathrm{BIT}_{i, j}+\beta_{10} A D T_{i, j}+\beta_{11} \operatorname{SOE}_{j, t}+\lambda Y E A R+\mu_{i, j, t}
\end{aligned}
$$

where $i$ represents the host country $i, j$ is China, $t$ represents the year, $\beta s$ are the coefficients to be estimated, $\lambda$ is the coefficient of the time trend, $\mu_{i t}$ is the disturbance term, and $L N$ denotes the transformation of natural logarithm.

\section{DATA AND EMPIRICAL ANALYSIS}

This paper employs the panel data of Chinese OFDI into 40 host countries from 2003 to 2010. 5All the sample countries have been receiving positive annual Chinese OFDI inflows from 2003 through 2010. Together, these countries account for more than $78.8 \%$ of Chinese OFDI in 2010 . All of the data comes from the China Stock Market and Accounting Research Database, the Statistical Bulletin of Chinese Foreign Direct Investment (2003-2010), the China Commerce Yearbook (2004-2008), the China Statistical Yearbook 2010, and the IMF International Financial Annual Report 2011.

Regression results for the full sample are presented in Table 1. Tests results of the geographic distance hypothesis: Regression results of geographic distance point to three conclusions. First, the coefficient of geographic distance is -1.13 and significant at the $1 \%$ level, implying that geographic distance hinders Chinese OFDI. Such a finding is consistent with hypothesis H1a as well as the fact that Chinese OFDI has 
been concentrated in Asia. Second, the coefficient of the cross-term of geographic and cultural distance is found to be insignificant, which does not support hypothesis H1b. It is possible that when Chinese MNEs undertake ODI on the US and European markets, their focus on energy resources and strategic assets could sideline their concerns over geographic and cultural distance. Third, the coefficient of the cross-term of geographic distance and bilateral trade is significant at the $1 \%$ level (LSDV1), which is consistent with hypothesis H1c. This could be due to the substitution effect between FDI and trade. The higher trade costs associated with greater geographic distance could discourage Chinese MNEs to enter a target country via ODI.

Test results of the cultural distance hypothesis: From the test results of cultural distance and the cross-terms, we draw the following conclusions. First, the coefficient of cultural distance is -2.55 and significant at the $5 \%$ level. This finding is consistent with hypothesis $\mathrm{H} 2 \mathrm{a}$ and the general observation that Chinese OFDI flows to countries with greater cultural similarity to Chinese culture. Based on the logic of the "outsider disadvantage" argument, the difficulties in perceiving and interpreting the host country environment and replicating tacit knowledge increase with cultural distance, resulting in the negative correlation between cultural distance and OFDI. Second, the coefficient of the cross-term of cultural distance and bilateral trade is 0.20 and significant at the 5\% level, suggesting cultural distance might promote Chinese OFDI by first affecting bilateral trade. The finding is inconsistent with hypothesis $\mathrm{H} 2 \mathrm{~b}$. There could be two possible reasons for such inconsistency. For one thing, based on the logic of the "outsider advantage" argument, when cultural distance is sufficiently high, the product differentiation advantage associated with cultural distance would gain prominence (Evans et al., 2002) and helps MNEs to tap the host country market. For another thing, culture related strategic assets are related but different in the home and the host country. In this case, there is a greater possibility for MNEs to expand their knowledge base and acquire new strategic assets through OFDI (Bjorkman et al., 2007).

Test results of the economic and politics hypothesis: When it comes to control variables, the coefficient of bilateral trade in LSDV2 is 0.46 and significant at the $1 \%$ level, confirming that trade promotes Chinese OFDI. This result is consistent with hypothesis $\mathrm{H} 3 \mathrm{~b}$ as well as anecdotal observations. Take the EU for example, the EU ranks among China's top 10 trading partners and is also the region witnessing the fastest growing Chinese OFDI. The coefficients of GDP growth rate and GDP per capita differentials are not significant in LSDV1, LSDV2 and LSDV3. Such results are inconsistent with H3a and H3c, but in line with Cheung (2009). This suggests that market seeking is not a predominant motive for Chinese OFDI. The sector location of Chinese OFDI in 2010 is highly illustrative of this point. In 2010, manufacturing and wholesale and retail trade accounted for $6.8 \%$ and $9.8 \%$ of total OFDI respectively while leasing and commercial services featuring advantageous assets accounted for $44 \% .{ }^{6}$ In terms of institutions, the coefficient of BIT is not significant, which is inconsistent with hypothesis H4a. The main reason is that China signed the existing BITs primarily for attracting FDI inflows rather than encouraging OFDI. The coefficient of ADT is shown to be negative. The reason could be that ADTs encourage both investment and trade. New Chinese enterprises could import intermediate products and machinery from China at relatively lower costs. Consequently, ADT plays a bigger role in encouraging trade than OFDI. Our result indicates reduced government control over OFDI. This is consistent with hypothesis H4b and the constantly declining percentages of SOEs of OFDI stock and that of the mining industry in OFDI flow.

The coefficient of time trend is significant at the $1 \%$ level, indicating that Chinese OFDI will continue to grow at a high speed. According to the Investment Development Cycle theory, with GDP per capita being in the third stage (US\$ 2500-4000), China is expected to experience OFDI growth greater than FDI.

\section{CONCLUDING REMARKS}

This study employs a panel data set of Chinese ODI in 40 host countries during the 2003-2010 period to explore the impact of geographic and cultural distance on OFDI. We first apply the LSDV model to the full sample and then to the sub-samples grouped by geographic and cultural distance. The results on the full sample shows that both geographic and cultural distance discourage Chinese OFDI. Regression results of the geographic distance sub-samples suggest that geographic distance significantly impedes Chinese OFDI in low distance countries, and its interaction with cultural distance reinforces such a negative effect. In contrast, geographic distance motivates Chinese OFDI when geographic distance is high. Regression results of the cultural distance sub-samples indicate that low cultural distance boosts Chinese OFDI, while high cultural distance exerts no obvious effect but has the potential to hinder OFDI by dampening bilateral trade. The findings have important implications for the Chinese MNEs going global. 
Qi et al., The Impacts of Geographic and Cultural Distance on Chinese ODI

\section{REFERENCES}

Anderson, J. E. (1979). The Theoretical Foundation for the Gravity Model. American Economic Review, 69, 106-116.

Benvan, A., Eatrin, S., and Meyer, K. (2004). Foreign Investment Location and Institution Development in Transition Economies. International Business Review, 13, 43-64.

Bjorkman, I., Stahl, G.K., and Vaara, E. (2007). Cultural Differences and Capability Transfer in CrossBorder Acquisitions: The Mediating Roles of Capability Complementary, Absorptive Capacity, and Social Integration. Journal of International Business Studies 38, 658-672.

Buckley, P., and Casson, M. (1981). The Optimal Timing of Foreign Direct Investment. Economic Journal, 91, 75-87.

Howard, J., and Cheng, I-Hui. (1999). Controlling for Heterogeneity in Gravity Models of Trade. Federal Reserve Bank of St. Louis Working Paper, 99-010A.

Cheung, Y.W., and Qian, X. W. (2009). Empirics of China's Outward Direct Investment. Pacific Economic Review, 14, 312-341.

Davies, K. (2010). Outward FDI from China and its policy context. Available at http://www.vcc.columbia.edu/files/vale/documents/China_OFDI_final_Oct_18.pdf, October .

Dow, D., and Karunaratna, A. (2006). Developing a Multidimensional Instrument to Measure Psychic Distance Stimulate. Journal of International Business Studies 37, 578-602.

Dunning, J. (1996). Explaining Foreign Direct Investment in Japan: Some Theoretical Insights. In Yoshitomo M. and Graham E. (Eds.), Foreign direct investment in Japan, Cheltenham, UK: Edward Elgar .

Edward, C. (2003). Foreign Direct Investment in Southeast Europe. Vienna Institute for International Economic Studies Working Paper 24.

Evans, J., and Mavondo, F. T. (2002). Psychic Distance and Organizational Performance: An Empirical Examination of International Retailing Operations. Journal of International Business Studies, 515-532.

Flores, R. G., and Aguilera, R. V. (2007). Globalization and Location Choice: An Analysis of US Multinational Firms in 1980 and 2000. Journal of International Business Studies, 38, 1187-1210.

Goldberg L., and Kolstad, C. (1995). Foreign Direct Investment, Exchange Rate Variability and Demand Uncertainty. International Economic Review, 36, 855-873.

Hofstede, G. (1980). Culture's Consequences: International Differences in Work-related Values, Beverly Hills: Sage Publications .

Kogut, B., and Singh, H. (1988). The Effect of National Culture on the Choice of Entry Mode. Journal of International Business Studies, 19, 411-432.

Kolstad, I., and Wiig, A. (2010). What Determines Chinese Outward FDI? Journal of World Business, 478, 124-132.

Korneliussena, T., and Blasiusb, J. (2008). The Effects of Cultural Distance, Free Trade Agreements, and Protectionism on Perceived Export Barriers. Journal of Global Marketing, 21, 217 -230.

Lu, J. W., and Beamish, P. W. (2004). International Diversification and Firm Performance: The S-Curve Hypothesis. Academy of Management Journal, 47, 598-609.

Matyas, L. (1997). Proper Economics Specification of the Gravity Model. The Word Economy, 20, 363-368.

Mucchielli Jean-Louis and Pei, Y. (2011). Do Newly Oligopolistic Reaction and Host Technology Resources Matter for MNC's Location? A Study in China's Technology Industries. Technology and Investment, 33, 171-183.

Scaperlanda, and Balough, R. S. (1983). Determinants of U.S. Direct Investment in the E.E.C. Revisited. European Economic Review, 21, 381-390.

Schneider, S. C. (1989). Strategy Formulation: The Impact of National Culture. Organization Studies, 10, 149-168.

Schwartz, S. H. (1994). Beyond Individualism/Collectivism: New Cultural Dimensions of Values. In Kim U., Triandis H. C., Kagitcibasi, C. Choi, S. C. and Yoon G. (Eds.), Individualism and Collectivism: Theory, Methods, and Applications, Thousand Oaks: Sage Publications .

Tinbergen, J. (1962). Shaping the World Economy, In An Analysis of World Trade Flows (Appendix V1), New York: Twentieth Century Fund.

Zaheer, S. (1995). Overcoming the Liability of Foreignness. Academy of Management Journal, 38, 341-363.

Zhang, X. J., and Daly, K. (2011). The Determinants of China's Outward Foreign Direct Investment. Emerging Markets Review, 1, 389-398. 